\title{
Inverse Relationship of Leucine Flux and Oxidation to Free Fatty Acid Availability In Vivo
}

\author{
Paolo Tessari, Steven L. Nissen, John M. Miles, and Morey W. Haymond \\ Endocrine Research Unit, Department of Pediatrics, Mayo Clinic and Mayo Foundation, Mayo Medical School, Rochester, Minnesota \\ 55905
}

\begin{abstract}
To determine the effect of fatty acid availability on leucine metabolism, 14-h fasted dogs were infused with either glycerol or triglyceride plus heparin, and 46-h fasted dogs were infused with either nicotinic acid or nicotinic acid plus triglyceride and heparin. Leucine metabolism was assessed using a simultaneous infusion of $\mathrm{L}-\left[4,5-{ }^{3} \mathrm{H}\right]$ leucine and $\alpha-\left[1-{ }^{14} \mathrm{C}\right]$ ketoisocaproate. Leucine, $\alpha-$ ketoisocaproate (KIC), and totalleucine carbon (leucine plus KIC) flux and oxidation rates were calculated at steady state. In 14$h$ fasted animals, infusion of triglyceride and heparin increased plasma free fatty acids (FFA) by $0.7 \mathrm{mM}(P<0.01)$ and decreased leucine $(P<0.01)$, total leucine carbon flux $(P<0.02)$, and oxidation $(P<0.05)$. The estimated rate of leucine utilization not accounted for by oxidation and KIC flux decreased, but the changes were not significant. During glycerol infusion, leucine and KIC flux and oxidation did not change.

In 46-h fasted dogs, nicotinic acid decreased FFA by $1.0 \mathrm{mM}$ $(P<0.01)$ and increased $(P<0.05)$ the rate of leucine and total leucine carbon flux, but did not affect KIC flux. Leucine oxidation increased $(P<0.01)$ by nearly threefold, whereas nonoxidized leucine utilization decreased. Infusion of triglyceride plus heparin together with nicotinic acid blunted some of the responses observed with nicotinic acid alone.

In that changes in oxidation under steady state condition reflect changes in net leucine balance, these data suggest that FFA availability may positively affect the sparing of at least one essential amino acid and may influence whole body protein metabolism.
\end{abstract}

\section{Introduction}

Prolonged fasting results not only in depletion of carbohydrate and fat stores, but also in the progressive loss of body protein ultimately resulting in inanition and death. Therefore, any mechanism which improves protein balance by decreasing proteolysis and/or oxidation of essential amino acids during inadequate caloric intake may improve the individual's duration of survival. Such relative sparing of body protein in fasted man

This work was presented in part at the European Society for Study of Diabetes in 1983.

At the time of this study Dr. Tessari was on leave from the Department of Patologia Medica and Malattie del Ricambio of the University of Padova, Italy. Address reprint requests to Dr. Haymond, Endocrine Research Unit, Mayo Clinic, Rochester, MN 55905.

Received for publication 29 June 1984 and in revised form 9 October 1985.

J. Clin. Invest.

(C) The American Society for Clinical Investigation, Inc.

0021-9738/86/02/0575/07 \$1.00

Volume 77, February 1986, 575-581 has been proposed on the basis of decreased excretion of urinary nitrogen and 3-methylhistidine in obese subjects fasted $21 \mathrm{~d}(1-$ 3). In most mammalian species, body protein cannot be totally conserved during prolonged periods of fasting, in contrast to the hibernating bear (4).

A variety of in vitro (5-7) and in vivo (8-13) experiments using isotopes of leucine have been carried out to determine the effects of fasting on amino acid and protein metabolism; however, the results of these studies are not entirely consistent. The oxidation of leucine by skeletal muscle is increased threefold in fasted when compared to fed rats, whereas protein synthesis, but not proteolysis, is decreased (7), suggesting that essential amino acids are not spared under these fasting conditions in this species. In 7-d fasted obese subjects, rates of leucine oxidation have also been reported to be increased when compared to the immediate postabsorptive period (13). In contrast, the results of leucine flux and oxidation studies in fasted dogs (12) and the results of leucine and lysine kinetic data and $\left[{ }^{15} \mathrm{~N}\right]$ glycine studies in fasted or partially fasted obese subjects, suggest a decreased whole body protein turnover (13-15).

During fasting, plasma glucose and insulin concentrations decrease, whereas those of free fatty acids (FFA), ${ }^{1}$ ketone bodies, and branched chain amino acids increase. Acute insulin withdrawal in somatostatin- and glucagon-infused dogs (16) results in an increase in leucine concentrations, and either in an increase or in no change in rate of appearance. Infusion of $\mathrm{Na} \mathrm{D,L- \beta -}$ hydroxybutyrate in man increased leucine nitrogen flux but did not affect the rate of leucine carbon flux (11). These data collectively suggest that neither a decrease in plasma insulin nor an increase in plasma ketone body concentrations per se is responsible for the decrease in leucine flux observed with fasting. It is possible that increased availability of FFA alone could account for the decrease in leucine flux and possibly oxidation observed with fasting $(12,13)$. Therefore, the present studies were designed to determine the effects of an acute increase or decrease of plasma FFA on leucine flux and oxidation in dogs.

\section{Methods}

Isotopes. $\mathrm{L}-\left[4,5-{ }^{3} \mathrm{H}\right]$ leucine $(100 \mathrm{mCi} / \mathrm{mmol})$ and $\mathrm{L}-\left[1-{ }^{14} \mathrm{C}\right]$ leucine $(55$ $\mathrm{mCi} / \mathrm{mmol}$ ) were purchased from Amersham Corp., Amersham, United Kingdom. $\left[1-{ }^{14} \mathrm{C}\right] \alpha$-ketoisocaproate (KIC) was prepared by the method of Rüdiger et al. (17) with final purification by high performance liquid chromatography (HPLC) $(18) . \mathrm{Na}\left[{ }^{14} \mathrm{C}\right] \mathrm{HCO}_{3}(66 \mathrm{mCi} / \mathrm{mmol})$ was obtained from New England Nuclear, Boston, MA.

Analytical methods. Plasma KIC concentrations and specific activities were determined by HPLC (18). Plasma leucine concentration and specific activity (SA) were determined using either a combination of HPLC and ion exchange chromatography $(12,19)$, or our recently developed HPLC method (18). Leucine containing aliquots derived from plasma

1. Abbreviations used in this paper: FFA, free fatty acids; HPLC, high performance liquid chromatography; KIC, $\alpha$-ketoisocaproate; SA, specific radioactivity; $\mathrm{TG}+\mathrm{H}$, triglyceride plus heparin. 
samples were collected in scintillation vials, scintillation cocktail added, and radioactivity determined by scintillation spectrometry. Radioactivity was corrected for quench and ${ }^{14} \mathrm{C}$ spillover into the tritium channel using an external standard method. No differences were observed in the leucine SA among the dogs analyzed by the two methods.

To estimate the rates of ${ }^{14} \mathrm{CO}_{2}$ expired, a funnel made from a plastic bottle and fitted with a rubber diaphragm was placed over the dog's muzzle and the expired air was directed either to the atmosphere or to a collection bag using a threeway valve. Expired air was collected in Douglas bags (Warren E. Collins, Inc., Braintree, MA) over a 2-min period, and the collected gas subsequently aspirated slowly through a 1 $\mathrm{M}$ ethanolamine solution to trap $\mathrm{CO}_{2}$. A $1.0-\mathrm{ml}$ aliquot of this solution was pipetted in triplicate into scintillation vials, scintillation cocktail added, and the ${ }^{14} \mathrm{C}$ radioactivity determined.

Plasma concentration of FFA (20), $\beta$-hydroxybutyrate, acetoacetate (2), lactate, and pyruvate (21) were determined as previously described. Plasma glucose concentrations were determined using a glucose oxidase method (Beckman II glucose analyzer; Beckman Instruments, Inc., Palo Alto, CA). The plasma concentration of insulin and glucagon was determined by radioimmunoassay $(22,23)$.

Experimental design. Healthy mongrel dogs weighing between 15 and $20 \mathrm{~kg}$ were used. Animals were housed in the Mayo Foundation animal care facility and fed a standard dry dog food (Dog Chow; Ralston Purina Co., Chow Div., St. Louis, MO). Dogs were fasted for either 14 or $46 \mathrm{~h}$ before the study as dictated by the protocols below, and allowed free access to water. The last meal before the study was offered under direct observation and entirely consumed within $5 \mathrm{~min}$.

On the morning of the study the dog was placed in a standing sling and two cephalic veins were cannulated with 18-gauge catheters. One vein was used for isotope infusions and the other for either triglyceride plus heparin $(\mathrm{TG}+\mathrm{H})$, nicotinic acid, or glycerol infusions. A catheter was also advanced through a saphenous vein to the proximity of the right atrium to obtain mixed central blood samples.

At -150 min, a primed-constant infusion of $\mathrm{L}-\left[4,5-{ }^{3} \mathrm{H}\right]$ leucine $(\sim 1.0$ $1.8 \mu \mathrm{Ci} / \mathrm{kg}, 0.02-0.03 \mu \mathrm{Ci} / \mathrm{kg} \cdot \min )$ and $\left[1-{ }^{14} \mathrm{C}\right] \mathrm{KIC}(\sim 0.05 \mu \mathrm{Ci} / \mathrm{kg}, 0.01$ $\mu \mathrm{Ci} / \mathrm{kg} \cdot \mathrm{min})$ was initiated. The bicarbonate pool was primed with a 4 $5 \mu \mathrm{Ci}$ bolus of $\left[{ }^{14} \mathrm{C}\right] \mathrm{HCO}_{3}$ to facilitate equilibration of ${ }^{14} \mathrm{CO}_{2}$ in expired air (24). Baseline samples for plasma substrate and SA determination and for expired ${ }^{14} \mathrm{CO}_{2}$ determination were collected at $-30,-20,-10$, and 0 time. Thereafter, animals were studied according to four different protocols. Four groups of dogs were studied.

Group I: $T G+H$. To acutely increase plasma FFA concentrations, seven 14-h fasted dogs were infused from 0 to $180 \mathrm{~min}$ with a $10 \%$ triglyceride-glycerol emulsion (Intralipid; Cutter Laboratories, Inc., Berkeley, CA) at $0.4 \mathrm{ml} / \mathrm{min}$. An intravenous bolus $(20 \mathrm{U} / \mathrm{kg})$ of $\mathrm{Na}$ heparin was administered at $0 \mathrm{~min}$ and subsequently at 30 -min intervals throughout the study.

Group II: glycerol. In order to distinguish between the effects of increased FFA and glycerol release upon hydrolysis of the triglyceride emulsion from those induced by the free glycerol present in the commercial lipid emulsion, four additional dogs were studied under identical conditions, except that they were infused with glycerol alone at a mean rate of $11 \mathrm{mg} / \mathrm{kg} \cdot \mathrm{min}$, which is comparable to the amount of free glycerol infused in group $\mathrm{I}$.

Group III: nicotinic acid. To determine the effects of an acute decrease in the plasma FFA concentration, six 46-h fasted dogs were infused for $150 \mathrm{~min}$ with a primed dose $(1 \mathrm{mg} / \mathrm{kg})$, continuous $(0.2 \mathrm{mg} / \mathrm{kg} \cdot \mathrm{min})$ infusion of nicotinic acid, a rate approximately twice that employed in man (25).

Group IV: nicotinic acid plus $T G+H$. In an attempt to control for potential direct effects of nicotinic acid, four additional animals were studied as described in group III above, except that triglyceride and heparin were infused as described in group $I$.

Calculations. Since plasma concentration of leucine and KIC and SA of $\left[{ }^{14} \mathrm{C}\right]$ - and $\left[{ }^{3} \mathrm{H}\right]$ leucine and $\left[{ }^{14} \mathrm{C}\right]-$ and $\left[{ }^{3} \mathrm{H}\right] \mathrm{KIC}$ were nearly constant during the periods of study, estimates of flux and oxidation were calculated assuming steady state conditions. The apparent rates of leucine flux were calculated using the following standard formula: $\left(r^{\left[{ }^{3} \mathrm{H}\right] \mathrm{lew}}\right) /\left(\mathrm{SA}^{\left[{ }^{3} \mathrm{H}\right] \mathrm{leu}}\right)$ where $r^{[3 \mathrm{H}] \text { leu }}$ is the rate of isotope infusion (dpm/kilograms $\cdot$ minutes) and $\mathrm{SA}^{\left[{ }^{3} \mathrm{H}\right] \text { leu }}$ is the $\mathrm{SA}$ of $\left[{ }^{3} \mathrm{H}\right]$ leucine in plasma. Similar calculations were carried out using the rate of $\left[{ }^{14} \mathrm{C}\right] \mathrm{KIC}$ and the plasma $\left[{ }^{14} \mathrm{C}\right] \mathrm{KIC} \mathrm{SA}$ to determine KIC flux. Total leucine carbon flux was calculated by adding the leucine and KIC flux. The apparent rates of leucine carbon oxidation were calculated using standard product-precursor relationships: apparent leucine carbon oxidation $=\left(\right.$ expired $\left.{ }^{14} \mathrm{CO}_{2}\right) /\left(\mathrm{SA}\left[{ }^{14} \mathrm{C}\right] \times 0.8\right)$ where expired ${ }^{14} \mathrm{CO}_{2}$ is the rate (dpm/kilograms - minutes) of ${ }^{14} \mathrm{CO}_{2}$ expired and $\mathrm{SA}$ $\left[{ }^{14} \mathrm{C}\right] \mathrm{KIC}$ is the plasma SA of $\left[1-{ }^{14} \mathrm{C}\right] \mathrm{KIC}$. The constant 0.8 represents the fractional recovery of ${ }^{14} \mathrm{CO}_{2}$ in expired breath during ${ }^{14} \mathrm{C}$-bicarbonate infusion and corrects for $\mathrm{CO}_{2}$ fixation and other losses. In addition, leucine carbon oxidation was calculated using the $\left[{ }^{14} \mathrm{C}\right]$ leucine SA (26), analogous to the use of $\left[{ }^{13} \mathrm{C}\right] \mathrm{KIC}$ enrichment during infusion of $\left[{ }^{13} \mathrm{C}\right]$ leucine (27). Leucine flux not accounted for by oxidation, an estimate of the rate of leucine entering protein, was calculated by substrating the rate of leucine oxidation using the $\left[{ }^{14} \mathrm{C}\right] \mathrm{KIC}$ SA or the rate of leucine oxidation using the $\left[{ }^{14} \mathrm{C}\right]$ leucine SA from the total (leucine plus $\mathrm{KIC}$ ) leucine carbon flux.

\section{Results}

Effects of $T G+H$ or glycerol infusions in 16- $h$ fasted dogs. During $\mathrm{TG}+\mathrm{H}$ infusion, plasma FFA increased $(P<0.01)$ from $0.5 \pm 0.1$ to $1.2 \pm 0.2 \mathrm{mM}$, whereas during glycerol infusion, FFA concentrations did not change $(0.6 \pm 0.1$ to $0.7 \pm 0.1 \mathrm{mM}$, Table I). Total ketone body concentrations, $(\beta$-hydroxybutyrate plus acetoacetate) were similar in both groups of dogs studied and did not change during either TG+H or glycerol infusions (Table I). The $\beta$-hydroxybutyrate/acetoacetate ratio decreased slightly with glycerol infusion and increased slightly with $\mathrm{TG}+\mathrm{H}$ infusion, but neither change was significant. No changes were observed in plasma glucose, lactate, pyruvate, insulin, or glucagon values with the infusion of either TG+H or glycerol (Table I), although some small differences were observed in baseline values between the two groups of animals studied.

Plasma leucine concentrations increased slightly with the glycerol infusion and were decreased slightly with TG+H infusion, but these changes were not significant (Table II). The plasma concentration of KIC decreased $(P<0.05)$ with glycerol infusion $(22 \pm 3$ to $16 \pm 1 \mu \mathrm{M})$ but was not affected by TG+H infusion (Table II). The ${ }^{3} \mathrm{H}$ - and ${ }^{14} \mathrm{C}$-SA of leucine and $\mathrm{KIC}$ remained constant during the glycerol infusion. In contrast, the $\left[{ }^{14} \mathrm{C}\right]$ - and $\left[{ }^{3} \mathrm{H}\right] l$ leucine SA increased during $\mathrm{TG}+\mathrm{H}$ infusion, but those of KIC remained constant. During glycerol infusion the rate of ${ }^{14} \mathrm{CO}_{2}$ expired increased $\left(9.1 \pm 0.9\right.$ to $11.6 \pm 3.0 \times 10^{-3}$ $\mathrm{dpm} / \mathrm{kg} \cdot \mathrm{min}$ ), primarily due to an increase in ${ }^{14} \mathrm{CO}_{2}$ expired in one dog; overall, no significant change in the rate of ${ }^{14} \mathrm{CO}_{2}$ expired was observed. During TG+H infusion, the rate of ${ }^{14} \mathrm{CO}_{2}$ expired decreased $(P<0.02)$ from $7.3 \pm 0.8$ to $5.6 \pm 0.5 \times 10^{-3} \mathrm{dpm} /$ $\mathrm{kg} \cdot \min ($ Table II).

During glycerol infusion, total leucine carbon entry $(6.59 \pm 0.41$ to $6.49 \pm 0.37 \mu \mathrm{mol} / \mathrm{kg} \cdot \mathrm{min})$ did not change. In contrast, the rate of total leucine carbon entry decreased from $7.04 \pm 0.83$ to $6.18 \pm 0.64 \mu \mathrm{mol} / \mathrm{kg} \cdot \min (P<0.02)$ during the $\mathrm{TG}+\mathrm{H}$ infusion as the result of a decrease in both leucine and KIC flux (Table III).

The rate of leucine oxidation increased during glycerol infusion, but this increase was not significant, regardless of the precursor pool SA used. In contrast, TG $+\mathrm{H}$ infusion resulted in a decrease in leucine oxidation, using either the $\left[{ }^{14} \mathrm{C}\right]$ leucine SA $(2.08 \pm 0.35$ to $1.25 \pm 0.16 \mu \mathrm{mol} / \mathrm{kg} \cdot \mathrm{min}, P<0.05)$, or the $\left[{ }^{14} \mathrm{C}\right] \mathrm{KIC} S A(0.88 \pm 0.19$ to $0.61 \pm 0.09 \mu \mathrm{mol} / \mathrm{kg} \cdot \min , P<0.02)$ (Table III). 
Table I. Effects of Glycerol, Triglycerides, and Nicotinic Acid Infusions on Plasma FFA, Ketone Bodies, Glucose, Lactate, Pyruvate, Insulin, and Glucagon Concentrations in Dogs

\begin{tabular}{|c|c|c|c|c|c|c|c|c|}
\hline & \multicolumn{2}{|l|}{ Glycerol } & \multicolumn{2}{|l|}{$\mathbf{T G}+\mathbf{H}$} & \multicolumn{2}{|l|}{ Nicotinic acid } & \multicolumn{2}{|c|}{ Nicotinic acid + TG+H } \\
\hline & Before & After & Before & After & Before & After & Before & After \\
\hline FFA $(m M)$ & $0.6 \pm 0.1$ & $0.7 \pm 0.1$ & $0.5 \pm 0.1$ & $1.2 \pm 0.2^{*}$ & $1.3 \pm 0.1$ & $0.3 \pm 0.1^{*}$ & $1.3 \pm 2$ & $0.7 \pm 0.2 \dagger$ \\
\hline \multicolumn{9}{|c|}{ Total ketone bodies $(\mu M)$} \\
\hline$(\beta \mathrm{OHB}+\mathrm{AcAc})$ & $140 \pm 33$ & $153 \pm 31$ & $89 \pm 8$ & $92 \pm 10$ & $208 \pm 25$ & $107 \pm 14$ & $156 \pm 24$ & $125 \pm 20 \dagger$ \\
\hline$\beta \mathrm{OHB} / \mathrm{AcAc}$ & $0.6 \pm 0.1$ & $0.5 \pm 0.1$ & $1.1 \pm 0.2$ & $1.5 \pm 0.3$ & $1.2 \pm 0.2$ & $0.5 \pm 0.1^{*}$ & $0.9 \pm 0.1$ & $0.7 \pm 0.2$ \\
\hline Glucose $(m g / d l)$ & $111 \pm 6$ & $114 \pm 8$ & $95 \pm 4$ & $98 \pm 4$ & $83 \pm 4$ & $99 \pm 6 \dagger$ & $79 \pm 5$ & $78 \pm 6$ \\
\hline Lactate $(m M)$ & $1.25 \pm 0.15$ & $1.37 \pm 0.13$ & $1.73 \pm 0.20$ & $1.47 \pm 0.19$ & $1.19 \pm 0.15$ & $1.40 \pm 0.24$ & $1.20 \pm 0.09$ & $1.24 \pm 0.14$ \\
\hline Pyruvate $(\mu M)$ & $55 \pm 19$ & $77 \pm 27$ & $42 \pm 13$ & $63 \pm 15$ & $40 \pm 10$ & $70 \pm 13 \dagger$ & $108 \pm 6$ & $118 \pm 10$ \\
\hline Insulin $(\mu U / m l)$ & $8 \pm 2$ & $6 \pm 1$ & $12 \pm 2$ & $10 \pm 1$ & $8 \pm 1$ & $7 \pm 1$ & $8 \pm 1$ & $8 \pm 1$ \\
\hline Glucagon $(p g / m l)$ & $67 \pm 7$ & $65 \pm 6$ & $173 \pm 31$ & $155 \pm 21$ & $145 \pm 30$ & $167 \pm 38$ & $123 \pm 19$ & $149 \pm 17 \dagger$ \\
\hline
\end{tabular}

* $P<0.01$. $\dagger P<0.05 . \beta \mathrm{OHB}+\mathrm{AcAc}, \beta$-hydroxybutyrate plus acetoacetate.

During glycerol infusion, the rate of leucine disappearance which could not be accounted for by oxidation decreased but the change was not significant (Table III). During TG+H infusion, the rate of leucine disappearance not accounted for by oxidation decreased $(P<0.05)$ using the $\left[{ }^{14} \mathrm{C}\right] \mathrm{KIC}$ SA for the calculation of leucine oxidation, but did not change when the rate of leucine oxidation was calculated from the $\left[{ }^{14} \mathrm{C}\right]$ leucine SA (Table III).

Effects of nicotinic acid and nicotinic acid plus $T G+H$ in 46$h$ fasted dogs. During infusion of nicotinic acid alone, plasma FFA decreased $(P<0.01)$ by $1.0 \mathrm{mM}$ from $1.3 \pm 0.1$ to $0.3 \pm 0.1$ $\mathrm{mM}$ and total plasma ketone bodies decreased $(P<0.01)$ by $101 \mu \mathrm{M}$ from $208 \pm 25$ to $107 \pm 14 \mu \mathrm{M}$ (Table I). The $\beta$-hydroxybutyrate/acetoacetate ratio decreased $(P<0.01)$ from $1.2 \pm 0.2$ to $0.5 \pm 0.1$. During combined infusion of nicotinic acid plus $\mathrm{TG}+\mathrm{H}$, intermediate responses were observed; plasma FFA and ketone bodies decreased $(P<0.01)$ by $0.6 \mathrm{mM}$ and $31 \mu \mathrm{M}$, respectively, and the $\beta$-hydroxybutyrate/acetoacetate ratio decreased (but not significantly) from 0.87 to 0.69 (Table I).

During nicotinic acid infusion, plasma glucose increased slightly $(P<0.01)$ from $83 \pm 4$ to $97 \pm 6 \mathrm{mg} / \mathrm{dl}$, whereas with the combined $\mathrm{TG}+\mathrm{H}$ and nicotinic acid infusion, plasma glucose did not change. Plasma lactate $(1.19 \pm 0.15$ to $1.40 \pm 0.24 \mu \mathrm{M}, P$ $<0.05)$ and pyruvate $(40 \pm 10$ to $70 \pm 13 \mu \mathrm{M}, P<0.02)$ concentrations increased during the nicotinic acid infusion, but the plasma concentrations of neither substrate were significantly changed during combined infusion (Table I). Plasma insulin decreased slightly from $8 \pm 1$ to $7 \pm 1 \mu \mathrm{U} / \mathrm{ml}(P<0.01)$ during the nicotinic acid infusion, but did not change during nicotinic acid plus $\mathbf{T G}+\mathbf{H}$ infusion. Plasma glucagon increased slightly during both studies, but the changes were significant $(P<0.01)$ only during the combined infusion study.

Plasma leucine and KIC concentrations did not change during the infusion of either nicotinic acid or nicotinic acid plus

Table II. Steady State Plasma Leucine and KIC Concentrations, SA, and Rates of

${ }^{14} \mathrm{CO}_{2}$ Expired Before and After Infusions of Glycerol, Triglyceride, and Nicotinic Acid in Dogs

\begin{tabular}{|c|c|c|c|c|c|c|c|c|}
\hline & \multicolumn{2}{|l|}{ Glycerol } & \multicolumn{2}{|l|}{$\mathbf{T G}+\mathbf{H}$} & \multicolumn{2}{|c|}{ Nicotinic acid } & \multicolumn{2}{|c|}{ Nicotinic acid + TG $+H$} \\
\hline & Before & After & Before & After & Before & After & Before & After \\
\hline \multicolumn{9}{|l|}{$\begin{array}{l}\text { Isotope infusion rate } \\
\qquad\left(\mathrm{dpm} \times 10^{-3} / \mathrm{kg} \cdot \mathrm{min}\right)\end{array}$} \\
\hline$\left[{ }^{3} \mathrm{H}\right]$ Leucine & \multicolumn{2}{|c|}{$59.18 \pm 5.09$} & \multicolumn{2}{|c|}{$59.15 \pm 6.38$} & \multicolumn{2}{|c|}{$40.20 \pm 3.39$} & \multicolumn{2}{|c|}{$66.99 \pm 5.44$} \\
\hline$\alpha\left[{ }^{14} \mathrm{C}\right]-$ Ketoisocaproate & \multicolumn{2}{|c|}{$25.03 \pm 5.25$} & \multicolumn{2}{|c|}{$21.45 \pm 1.71$} & \multicolumn{2}{|c|}{$25.95 \pm 3.04$} & \multicolumn{2}{|c|}{$16.96 \pm 0.92$} \\
\hline \multicolumn{9}{|l|}{ Leucine } \\
\hline Concentrations $(\mu M)$ & $130 \pm 9$ & $134 \pm 11$ & $137 \pm 8$ & $123 \pm 9$ & $199 \pm 8$ & $215 \pm 10$ & $188 \pm 15$ & $198 \pm 30$ \\
\hline${ }^{3} \mathrm{H}-\mathrm{SA}(\mathrm{dpm} / \mathrm{nmol})$ & $12.1 \pm 1.2$ & $12.3 \pm 0.8$ & $13.4 \pm 1.2$ & $15.5 \pm 1.1^{*}$ & $11.9 \pm 0.8$ & $10.4 \pm 1.0^{*}$ & $20.9 \pm 1.9$ & $18.2 \pm 2.2 \dagger$ \\
\hline${ }^{14} \mathrm{C}-\mathrm{SA}(\mathrm{dpm} / \mathrm{nmol})$ & $4.3 \pm 0.8$ & $3.6 \pm 0.8$ & $3.9 \pm 0.5$ & $4.8 \pm 0.6^{*}$ & $6.6 \pm 0.3$ & $5.2 \pm 0.3^{*}$ & $4.8 \pm 0.3$ & $4.0 \pm 0.4 \dagger$ \\
\hline \multicolumn{9}{|l|}{$\alpha$-Ketoisocaproate } \\
\hline Concentrations $(\mu M)$ & $22 \pm 3$ & $16 \pm 1 \dagger$ & $13 \pm 1$ & $14 \pm 1$ & $24 \pm 2$ & $22 \pm 2$ & $15 \pm 2$ & $16 \pm 2$ \\
\hline${ }^{14} \mathrm{C}-\mathrm{SA}(\mathrm{dpm} / \mathrm{nmol})$ & $16.4 \pm 4.0$ & $15.3 \pm 3.4$ & $9.6 \pm 1.3$ & $9.9 \pm 0.9$ & $10.0 \pm 0.2$ & $9.8 \pm 0.9$ & $8.3 \pm 0.6$ & $8.2 \pm 0.7$ \\
\hline${ }^{3} \mathrm{H}-\mathrm{SA}(d p m / n m o l)$ & $10.1 \pm 1.4$ & $9.3 \pm 1.1$ & $8.0 \pm 1.4$ & $9.0 \pm 1.2$ & $8.4 \pm 0.5$ & $7.1 \pm 0.5$ & $14.6 \pm 1.7$ & $13.0 \pm 1.3$ \\
\hline $\begin{array}{l}\text { Expired }{ }^{14} \mathrm{CO}_{2} \\
\quad\left(\mathrm{dpm} \times 10^{-3} / \mathrm{kg} \cdot \mathrm{min}\right)\end{array}$ & $9.1 \pm 0.9$ & $11.6 \pm 3.0$ & $7.3 \pm 0.8$ & $5.6 \pm 0.5 \S$ & $8.1 \pm 0.9$ & $16.5 \pm 1.7^{*}$ & $4.7 \pm 0.7$ & $7.8 \pm 0.9 *$ \\
\hline
\end{tabular}

Data are expressed as mean $\pm \mathrm{SE}$, see Methods for details of the experimental design. $* P<0.01$ cf before value. $\dagger P<0.05$ cf before value. $\S P$ $<0.02$ cf before value. 
Table III. Effects of Glycerol, TG+H, and Nicotinic Acid Infusions on Leucine and $\alpha$-Ketoisocaproate Metabolism in Dogs

\begin{tabular}{|c|c|c|c|c|c|c|c|c|}
\hline & \multicolumn{2}{|l|}{ Glycerol } & \multicolumn{2}{|l|}{$\mathbf{T G}+\mathbf{H}$} & \multicolumn{2}{|l|}{ Nicotinic acid } & \multicolumn{2}{|c|}{ Nicotinic acid + TG+H } \\
\hline & Before & After & Before & After & Before & After & Before & After \\
\hline \multicolumn{9}{|l|}{ Rate of appearance } \\
\hline Leucine & $4.96 \pm 0.24$ & $4.79 \pm 0.20$ & $4.54 \pm 0.48$ & $3.86 \pm 0.36 \dagger$ & $3.20 \pm 0.19$ & $3.76 \pm 0.37 \S$ & $3.27 \pm 0.33$ & $3.87 \pm 0.52$ \\
\hline KIC & $1.63 \pm 0.17$ & $1.69 \pm 0.18$ & $2.51 \pm 0.41$ & $2.32 \pm 0.32$ & $2.30 \pm 0.14$ & $2.51 \pm 0.35$ & $2.05 \pm 0.10$ & $2.13 \pm 0.22$ \\
\hline Leucine + KIC & $6.59 \pm 0.41$ & $6.49 \pm 0.37$ & $7.04 \pm 0.83$ & $6.18 \pm 0.64 \ddagger$ & $5.50 \pm 0.30$ & $6.27 \pm 0.68$ & $5.32 \pm 0.40$ & $6.00 \pm 0.74$ \\
\hline \multicolumn{9}{|l|}{ Rate of disappearance } \\
\hline Using $\left[{ }^{14} \mathrm{C}\right] \mathrm{KIC} \mathrm{SA}$ & $0.69 \pm 0.14$ & $0.80 \pm 0.13$ & $0.88 \pm 0.19$ & $0.61 \pm 0.09 \S$ & $0.64 \pm 0.06$ & $1.64 \pm 0.22 \dagger$ & $0.57 \pm 0.09$ & $1.01 \pm 0.21 \S$ \\
\hline Using $\left[{ }^{[4} \mathrm{C}\right]$ leucine SA & $2.44 \pm 0.37$ & $3.74 \pm 0.88$ & $2.08 \pm 0.35$ & $1.25 \pm 0.16 \ddagger$ & $0.95 \pm 0.05$ & $2.95 \pm 0.24 \dagger$ & $1.03 \pm 0.24$ & $2.14 \pm 0.48 \S$ \\
\hline \multicolumn{9}{|c|}{$\begin{array}{l}\text { Rate of disappearance not } \\
\text { accounted for by oxidation }\end{array}$} \\
\hline oxidation & $5.90 \pm 0.34$ & $5.69 \pm 0.27$ & $6.16 \pm 0.66$ & $5.57 \pm 0.55 \ddagger$ & $4.87 \pm 0.30$ & $4.63 \pm 0.54$ & $4.76 \pm 0.32$ & $4.99 \pm 0.55$ \\
\hline $\begin{array}{l}\text { Using }\left[{ }^{14} \mathrm{C}\right] \text { leucine SA f } \\
\text { oxidation }\end{array}$ & $4.15 \pm 0.42$ & $2.75 \pm 0.81$ & $4.97 \pm 0.54$ & $4.93 \pm 0.50$ & $4.55 \pm 0.28$ & $3.32 \pm 0.51 \S$ & $4.29 \pm 0.22$ & $3.86 \pm 0.26$ \\
\hline
\end{tabular}

* All data expressed as mean $\pm \mathrm{SE}, \mu \mathrm{mol} / \mathrm{kg} \cdot \mathrm{min} . \quad \dagger P<0.01 \mathrm{cf}$ before value. $\S P<0.05 \mathrm{cf}$ before value. $¥ P<0.02 \mathrm{cf}$ before value.

$\mathrm{TG}+\mathrm{H}$. During both infusion studies, the ${ }^{3} \mathrm{H}$ - and ${ }^{14} \mathrm{C}-\mathrm{SA}$ of leucine decreased $(P<0.01$ with nicotinic acid; $P<0.05$ with nicotinic acid plus $\mathrm{TG}+\mathrm{H}$, Table II); although the $\left[{ }^{3} \mathrm{H}\right]-$ and $\left[{ }^{14} \mathrm{C}\right] \mathrm{KIC} \mathrm{SA}$ decreased under both study conditions, these changes were not significant. The rate of $\left[{ }^{14} \mathrm{C}\right] \mathrm{CO}_{2}$ expired increased $(P<0.01)$ during both infusion periods (Table II), but this increase was blunted during the combined infusion of nicotinic acid plus $\mathrm{TG}+\mathrm{H}$.

Infusion of nicotinic acid alone resulted in an increase $(P$ $<0.05)$ in the rate of leucine entering the vascular space $(3.20 \pm 0.19$ to $3.75 \pm 0.37 \mu \mathrm{mol} / \mathrm{kg} \cdot \mathrm{min}$, Table III). The rate of appearance of KIC increased, but the change was not significant (Table III). Although the entry of leucine and KIC increased, the changes only approached the level of significance $(0.05>P$ $>0.10$ ).

During the combined infusion of nicotinic acid plus $\mathrm{TG}+\mathrm{H}$, leucine, KIC, and leucine plus KIC entry increased, but the changes were not significant (Table III). During the nicotinic acid infusion, leucine oxidation increased $(P<0.01)$ two- to threefold regardless of whether $\left[{ }^{14} \mathrm{C}\right] \mathrm{KIC}$ or $\left[{ }^{14} \mathrm{C}\right]$ leucine SA was used (Table III). During combined infusion of nicotinic acid plus TG $+\mathrm{H}$, leucine carbon oxidation increased $(P<0.05$ or $<0.01$ depending on the precursor used) twofold regardless of the model used (Table III).

The rate of nonoxidized leucine disappearance during nicotinic acid infusion alone decreased regardless of the precursor pool SA used for the calculation of leucine oxidation, but the decrease was only significant $(P<0.05)$ using the $\left[{ }^{14} \mathrm{C}\right]$ leucine SA $(4.55 \pm 0.28$ to $3.32 \pm 0.51 \mu \mathrm{mol} / \mathrm{kg} \cdot \mathrm{min}$, (Table III). During infusion of nicotinic acid plus $\mathrm{TG}+\mathrm{H}$, rate of disappearance of leucine not accounted for by oxidation did not change significantly regardless of which precursor pool SA was used for calculating leucine oxidation (Table III).

In a limited number of experiments $(n=3)$ using a constant infusion of only $\mathrm{H}^{14} \mathrm{CO}_{3}$, a 5-20\% increase in the rate of expired
$\mathrm{H}^{14} \mathrm{CO}_{3}$ was observed following initiation of the nicotinic acid infusion. If this occurred during the studies of leucine kinetics employing nicotinic acid, this small increase in ${ }^{14} \mathrm{CO}_{2}$ expired (or decrease in $\mathrm{CO}_{2}$ fixation) due to nicotinic acid's effect on expired ${ }^{14} \mathrm{CO}_{2}$ would result in a slight overestimation in the rate of leucine carbon oxidation; however, since leucine oxidation increased $250-300 \%$, any error in the estimation of expired ${ }^{14} \mathrm{CO}_{2}$ on this basis would be negligible.

Correlations. Inverse correlations were found between the changes in plasma FFA concentrations and estimates of rates of leucine carbon oxidation (using $\left[{ }^{14} \mathrm{C}\right] \mathrm{KIC}$ SA, $r=-0.806, P$ $<0.001$, or using $\left[{ }^{14} \mathrm{C}\right]$ leucine SA, $r=-0.762, P<0.001$, Fig. 1). Changes in plasma FFA concentrations were inversely correlated with the rate of appearance of leucine $(r=-0.713, P$ $<0.001)$ and with total leucine carbon (leucine $+\mathrm{KIC})(r=$ $-0.612, P<0.003)$. Changes in FFA did not correlate with the rate of appearance of $\mathrm{KIC}$ or with the estimates of nonoxidized leucine disappearance using $\left[{ }^{14} \mathrm{C}\right]$ leucine as the precursor pool for oxidation. A weak $(r=0.451)$ but significant $(P<0.04)$ inverse correlation was observed between $\triangle$ FFA and nonoxidized leucine disappearance using the $\left[{ }^{14} \mathrm{C}\right] \mathrm{KIC}$ SA.

Changes in total ketone body concentrations correlated inversely with the rate of leucine oxidation using $\left[{ }^{14} \mathrm{C}\right] \mathrm{KIC}(r$ $=-0.473, P<0.004)$ or using $\left[{ }^{14} \mathrm{C}\right]$ leucine, as well as with both the rate of appearance of leucine $(r=-0.576, P<0.05)$ and of total leucine carbon $(r=-0.435, P<0.05)$. Again, changes in total ketone body concentrations did not correlate with the estimated rates of appearance of KIC or nonoxidized leucine disappearance. Changes in $\beta$-hydroxybutyrate/acetoacetate ratio were inversely correlated with changes in leucine apparent oxidation $(r=-0.470, P<0.05)$.

However, when multiple regression analysis was performed between changes in FFA and total ketone bodies as independent variables and each of the above mentioned parameters of leucine metabolism as dependent variable(s) only changes in FFA con- 

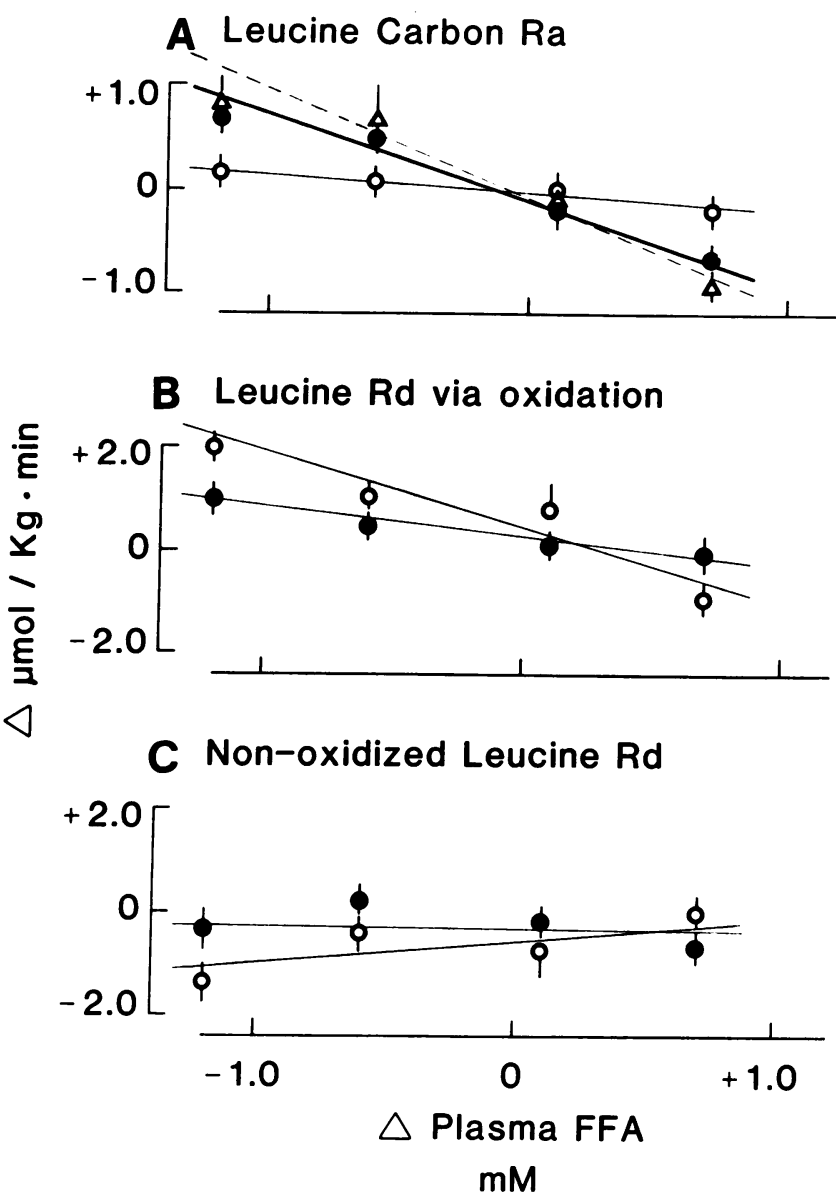

Figure 1. The effects of changes in plasma FFA concentration on changes in leucine rate of appearance ( $\mathrm{Ra}$ ) and rate of disappearance (Rd) attributable to oxidative and nonoxidative processes. Changes in FFA concentrations were induced by infusions of saline, TG+H, nicotinic acid, or a combination of nicotinic acid and TG+H. $(A)-\mathrm{O}-$, $\mathrm{KIC} \operatorname{Ra}(r=-0.299, P=\mathrm{NS}) ;-\bullet-$, leucine Ra $(r=-0.713$, $P<0.001)$; $-\Delta$-, leucine plus KIC Ra $(r=-0.612, P<0.003)$. (B) - - - using $\left[{ }^{14} \mathrm{C}\right] \mathrm{KIC}(r=-0.806, P<0.001) ;-0-$, using $\left[{ }^{14} \mathrm{C}\right]$ leucine $(r=-0.762, P<0.001) .(C)-\bullet-$, using $\left[{ }^{14} \mathrm{C}\right] \mathrm{KIC}$ for oxidation $(P=\mathrm{NS}) ;-\mathrm{O}-$, using $\left[{ }^{14} \mathrm{C}\right]$ leucine for oxidation $(r$ $=0.451, P<0.04)$.

centrations resulted in significant correlations $(P<0.01)$ with changes in leucine carbon oxidation and flux rates, while changes in ketone body concentrations did not.

\section{Discussion}

Fasting is associated with complex changes in the circulating concentrations of hormones and substrates, rates of substrate flux and interconversion, and energy expenditure. Therefore, it is difficult to determine the role and/or effects of alterations in availability of a single substrate, such as fatty acids, from fasting studies alone. The present studies demonstrate that acute changes in plasma FFA concentrations within the physiologic range observed with feeding and fasting via the infusion of triglyceride, heparin, and/or nicotinic acid are inversely related to estimates of whole body leucine carbon flux and oxidation, but not with estimates of leucine disappearance unaccounted for by oxidation (a possible indicator of the rate of leucine entering protein). As- suming that the only source of plasma leucine in the postabsorptive state is endogenous protein, and that there is no accumulation of intracellular free leucine, we conclude that FFA availability is inversely related to the rate of whole body proteolysis and of the oxidation of at least one essential amino acid, leucine. As a result, at least some of the changes in leucine metabolism observed in both the fasted $(12,13)$ and fed $(28-30)$ states may be linked to changes in FFA availability.

During periods of fasting which are associated with increases in plasma FFA concentrations, decreased rates of whole body leucine and lysine flux have been observed in both man $(13,14)$ and $\operatorname{dog}(12,28)$. These observations are consistent with a decrease in protein turnover and/or a fasting-induced protein sparing effect (15). A decrease in whole body leucine oxidation has been observed in some $(12,28)$, but not all $(13)$ reports and is consistent with a decrease in urinary nitrogen excretion observed with fasting in man $(2,15)$. Adibi and co-workers (13) reported decreased leucine flux, but increased leucine oxidation in obese humans consuming $80 \mathrm{kcal} / \mathrm{d}$ for $7 \mathrm{~d}$; this would result in a greater fraction of the leucine flux being oxidized. Their results would not be consistent with the predominance of published data outlined above, demonstrating a nitrogen and/or an amino acid sparing effect of fasting.

Nicotinic acid, a potent inhibitor of lipolysis, has been reported to increase urea excretion and amino acid oxidation in fasted animals (31-34). These results are thought to be related to the effect of nicotinic acid on the availability of lipid-derived fuels, resulting in increased utilization of other substrates (e.g., amino acids and glucose) as metabolic fuels, and not a direct effect of the drug $(32,33)$. However, nicotinic acid, by direct or indirect effect, decreases the hepatic reduced nicotinamide-adenine dinucleotide/nicotinamide-adenine dinucleotide (NADH/ NAD) ratio (35) and in the present study decreased the plasma $\beta$-hydroxybutyrate/acetoacetate ratio (Table I). The activity of the branched chain $\alpha$-ketoacid dehydrogenase complex $(36,37)$ and rates of proteolysis (38) have been linked to alterations in the NADH/NAD ratio; therefore, changes in cellular redox could account for the increased rates of leucine flux and oxidation observed in the present studies during nicotinic acid infusion, as well as during the infusion of triglyceride and heparin (39). Although the changes in the $\beta$-hydroxybutyrate/acetoacetate ratio in the present studies are consistent with the purported effect of changes in NADH/NAD on leucine flux and oxidation, changes in the lactate/pyruvate ratio (an indicator of the cytosolic redox state) were not. In addition, neither the plasma concentrations of these substrates ( $\beta$-hydroxybutyrate, acetoacetate, lactate, pyruvate) nor their ratios ( $\beta$-hydroxybutyrate/acetoacetate or lactate/pyruvate) correlated by multiple regression analysis with changes in leucine flux or oxidation. However, since the plasma $\beta$-hydroxybutyrate/acetoacetate and lactate/pyruvate ratios are only indirect indicators of cellular redox state, we cannot exclude the possibility that changes in cellular redox (whether a direct effect of either FFA and/or nicotinic acid) do not underlie, at least in part, the changes in leucine (and presumably protein) metabolism observed in the present studies. It should be pointed out that the addition of $\mathrm{TG}+\mathrm{H}$ infusion to nicotinic acid infusion had no substantial effect on leucine carbon flux estimates when compared to nicotinic acid infusion alone $(\Delta 0.68$ vs. $0.77 \mu \mathrm{mol} / \mathrm{kg} \cdot \mathrm{min}$, respectively, Table III), whereas the nicotinic acid-induced increase in estimates of leucine oxidation were decreased by $\sim 50 \%$ with the addition of $\mathrm{TG}+\mathrm{H}$ infusion. 
As a result, we cannot establish with certainty that the changes observed in leucine metabolism during nicotinic acid infusion were directly attributable to changes in fatty acid availability as estimated by changes in the plasma concentration of FFA.

Regardless of the experimental perturbation, the changes in total leucine carbon flux (leucine plus KIC) are almost entirely attributable to changes in leucine flux alone since the KIC flux did not change significantly. However, in all cases the KIC flux changed in the same direction as the leucine flux. The reasons for this apparent discrepancy in the magnitude of change in the rate of appearance of leucine and KIC into the plasma space is not clear. The isotope model utilized assumes equal efficiency of removal of the leucine and KIC labels from the plasma space. Under the experimental conditions employed, changes in plasma substrate concentration might differentially affect the transport of the labels to the intracellular space; therefore the resultant changes in leucine and KIC SA and the flux estimates derived from these SA may not be proportional. However, the differential changes in leucine and KIC flux may suggest some fundamental differences in the metabolism of leucine and its $\alpha$-ketoacid which remain to be elucidated.

The present studies demonstrate the potential importance of fatty acid availability in protein sparing, and are consistent with an increase in protein wasting (increased total leucine carbon flux and oxidation) under situations in which fatty acid fuel availability is limited. Since the present studies were carried out over short periods of time and nitrogen balance was not accessed, no conclusion can be drawn regarding the availability of FFA over either short or long term periods of time on whole body protein metabolism. Whether increasing plasma FFA via the infusion of triglycerides has advantages when simultaneously infused with other substrates such as glucose and amino acids, as occurs during parenteral nutrition, remains to be clearly established.

\section{Acknowledgments}

We wish to thank Ms. Carol van Huysen, Ms. Collette Schmidt, Ms. Joan Aikens, and Mr. Peter Berg for their technical assistance, Ms. Marylee Campion for her secretarial help, and Dr. A. Piccoli for his help in performing the multiple regression analyses.

This work was supported by National Institutes of Health grant AM26989, and the Wasie and Mayo Foundations. Dr. Nissen was supported by National Institutes of Health grant AM-07352. Dr. Tessari was supported by a grant from the Consiglio Nazionale delle Ricerche of Italy.

\section{References}

1. Cahill, G. F., Jr. 1970. Starvation in man. N. Engl. J. Med. 282: 668-675.

2. Cahill, G. F., Jr., M. G. Herrera, A. P. Morgan, J. Soeldner, J. Steinke, P. L. Levy, G. A. Richards, and D. M. Kipnis. 1966. Hormone fuel interrelationship during fasting. J. Clin. Invest. 45:1751-1759.

3. Young, V. R., L. N. Havenberg, C. Bilmazes, and H. N. Munroe. 1973. Potential use of $N$-methylhistidine as an index of progression reduction in muscle protein catabolism during starvation. Metab. Clin. Exp. 22:1429-1436.

4. Lundberg, D. A., R. A. Nelson, H. W. Wahner, and J. D. Jones. 1976. Protein metabolism in the black bear before and during hibernation. Mayo Clin. Proc. 51:716-722.

5. Buse, M. G., J. F. Bigger, K. H. Friderici, and J. C. Buse. 1972. Oxidation of branched chain amino acids by isolated hearts and diaphragms of the rat: the effects of fatty acids, glucose and pyruvate respiration. J. Biol. Chem. 247:8085-8096.

6. Hutson, S. M., T. C. Cree, and A. E. Harper. 1978. Regulation of leucine and $\alpha$-ketoisocaproate metabolism in skeletal muscle. J. Biol. Chem. 253:8126-8133.

7. Goldberg, A. L., and R. Odessey. 1972. Oxidation of amino acids by diaphragms from fed and fasted rats. Am. J. Physiol. 223:1384-1391.

8. Golden, M. H. N., and J. C. Waterlow. 1977. Total protein synthesis in elderly people: a comparison of results with $\left[{ }^{15} \mathrm{~N}\right]$ glycine and $\left[{ }^{14} \mathrm{C}\right]$ leucine. Clin. Sci. Mol. Med. 53:277-288.

9. Matthews, D. E., K. J. Motil, D. K. Rohrbaugh, J. E. Burke, V. R. Young, and D. M. Bier. 1980. Measurement of leucine metabolism in man from a primed constant infusion of $\mathrm{L}-\left[1-{ }^{13} \mathrm{C}\right]$ leucine. $\mathrm{Am} . \mathrm{J}$. Physiol. 238:E473-E479.

10. Wolfe, R. R., R. D. Goodenough, M. H. Wolfe, G. T. Royle, and E. R. Nadel. 1982. Isotopic analysis of leucine and urea metabolism in exercising humans. Am. J. Physiol. 52:458-466.

11. Miles, J. M., S. L. Nissen, R. A. Rizza, J. E. Gerich, and M. W. Haymond. 1983. Failure of infused beta-hydroxybutyrate to decrease proteolysis in man. Diabetes. 32:197-205.

12. Nissen, S., and M. W. Haymond. 1981. Effects of fasting on flux and interconversion of leucine and $\alpha$-ketoisocaproate in vivo. Am. $J$. Physiol. 241:E72-E75.

13. Adibi, S. A., R. T. Stanko, and E. L. Morse. 1982. Modulation of leucine oxidation and turnover by graded amounts of carbohydrate intake in obese subjects. Metab. Clin. Exp. 31:578-588.

14. Henson, L., and D. Heber. 1983. Whole body protein breakdown rates and hormonal adaptation in fasted obese subjects. J. Clin. Endocrinol. Metab. 57:316-319.

15. Bistrian, B. R., M. Sherman, and V. R. Young. 1981. The mechanism of nitrogen sparing in fasting supplemented by protein and carbohydrate. J. Clin. Endocrinol. Metab. 53:874-878.

16. Abumerad, N. N., L. S. Jefferson, S. R. Rannels, P. E. Williams, A. D. Cherrington, and W. W. Lacy. 1982. Role of insulin in the regulation of leucine kinetics in the conscious dog. J. Clin. Invest. 70:10311041.

17. Rüdiger, H. W., V. Langenbeck, and H. W. Goedde. 1972. A simplified method for preparation of ${ }^{14} \mathrm{C}$ labeled branched chain alphaoxoacid. Biochem. J. 126:445-446.

18. Nissen, S. L., C. Van Huysen, and M. W. Haymond. 1982. Measurement of branched chain amino acids and branched chain ketoacids by high performance liquid chromatography. J. Chromatogr. 232:170175.

19. Stacey-Schmidt, C., P. Berg, and M. W. Haymond. 1982. Use of D-glucosaminic acid as internal standard in single column accelerated amino acid analysis. Anal. Biochem. 123:74-77.

20. Miles, J., R. Glasscock, J. Aikens, J. Gerich, and M. Haymond. 1983. A microfluorometric method for the determination of free fatty acids in plasma. J. Lipid Res. 24:96-99.

21. Lowry, O. H., and J. V. Passonneau. 1972. A Flexible System of Enzymatic Analysis. Academic Press, Inc., New York. 148-212.

22. Herbert, V., K. Lau, C. Gohlich, and S. Blaeicher. 1965. Coated charcoal immunoassay of insulin. J. Clin. Endocrinol. Metab. 25:13751379.

23. Faloona, G., and R. Unger. 1974. Glucagon. In Methods of Hormone Radioimmunoassay. B. Jaffe and H. Behrman, editors. Academic Press, Inc., New York. 317-330.

24. Allsop, J. R., R. R. Wolfe, and J. F. Burke. 1978. Tracer priming the bicarbonate pool. Am. J. Physiol. 45:137-139.

25. Carlson, L. A., R. J. Havel, L. Ekelund, and A. Holmgren. 1963. Effect of nicotinic acid on the turnover rate and oxidation of the free fatty acids of plasma in man during exercise. Metab. Clin. Exp. 12:837845 .

26. Schwenk, W. F., B. Beaufrere, and M. W. Haymond. 1985. Use of reciprocal pool specific activities to model leucine metabolism in man. Am. J. Physiol. 249:E646-E650.

27. Matthews, D. E., H. P. Schwartz, R. D. Yang, K. J. Motil, and V. R. Young. 1982. Relationship of plasma leucine and $\alpha$-ketoisocaproate during an $\mathrm{L}-\left[1-{ }^{13} \mathrm{C}\right]$ leucine infusion in man: a method for measuring human intracellular leucine tracer enrichment. Metab. Clin. Exp. 31: $1105-1112$. 
28. Abumrad, N. N., P. E. Williams, K. W. Wise, D. B. Lacy, and W. W. Lacy. 1981. The effect of starvation on leucine kinetics in the conscious dog. In Metabolism and Clinical Implications of Branched Chain Amino and Ketoacids. M. Walser and J. R. Williamson, editors. Elsevier/North-Holland Publishers, New York. 355-360.

29. Motil, K. J., D. M. Bier, D. E. Matthews, J. F. Burke, and V. R. Young. 1981. Whole body leucine and lysine metabolism studied with $\left[1-{ }^{13} \mathrm{C}\right]$ leucine and $\left[-{ }^{15} \mathrm{~N}\right] \mathrm{lysine}$ : response in healthy young men given excess energy intake. Metab. Clin. Exp. 30:783-791.

30. Motil, K. J., D. E. Matthews, D. M. Bier, J. F. Burke, H. N. Munro, and V. R. Young. 1981. Whole body leucine and lysine metabolism: response to dietary protein intake in young men. Am. J. Physiol. 240:E712-E721.

31. Gey, K. F., K. von Berlepsch, H. Malanowsky, and E. Lorch. 1970. Increase of urea formation by nicotinic acid and $\beta$-pyridylcarbinol in the starved rat. In Metabolic Effects of Nicotinic Acid and Its Derivatives. Gey and Carlson, editors. Hans Huber, Bern, Switzerland. 10351044.

32. Trout, D. L., H. L. Bitter, and W. W. Lackey. 1967. Effects of nicotinic acid on the choice of substrates utilized during fasting. Biochem. Pharmacol. 61:971-978.

33. Hasselblatt, A., U. Pante, and W. Poser. 1970. The stimulatory effect of antilipolytic compounds on amino acid metabolism and urea synthesis in rat. In Metabolic Effects of Nicotinic Acid and Its Derivatives. Gey and Carlson, editors. Hans Huber, Bern, Switzerland. 1023-1033.

34. Exton, J. H., S. B. Lewis, and C. R. Park. 1970. Examination of in vitro effects of nicotinic acid on basal and hormone-stimulated glycogenolysis, gluconeogenesis, ureogenesis, and ketogenesis in the isolated perfused rat liver. In Metabolic Effects of Nicotinic Acid and Its Derivatives. Gey and Carlson, editors. Hans Huber, Bern, Switzerland. 851859.

35. Williamson, D. H., F. Mayor, D. Velosa, and S. S. Page. 1970. Effects of nicotinic acid and related compounds on ketone body metabolism. In Metabolic Effects of Nicotinic Acid and Its Derivatives. Gey and Carlson, editors. Hans Huber, Bern, Switzerland. 227-236.

36. Buse, M. G., H. F. Herlong, and D. A. Weigand. 1976. The effect of diabetes, insulin, and the redox potential on leucine metabolism by isolated rat hemidiaphragm. Endocrinology. 98:1166-1175.

37. Harris, R. A. S., and R. Paxton. 1985. Regulation of branched chain $\alpha$-ketoacid dehydrogenase complex by phosphorylation-dephosphorylation. Fed. Proc. 44:305-315.

38. Tischler, M. E., and J. M. Fagan. 1982. Relationship of the reduction-oxidation state to protein degradation in skeletal and atrial muscle. Arch. Biochem. Biophys. 217:191-201.

39. Williamson, J. R., E. Walajtys-Rode, and K. E. Coll. 1979. Effects of branched chain $\alpha$-ketoacids on the metabolism of isolated rat liver cells. J. Biol. Chem. 254:11511-11520. 